\title{
$\mathbb{D r} \mathfrak{i} \mathfrak{i} \mathfrak{i} \mathfrak{i} \mathfrak{I} \mathfrak{I} \mathfrak{a} \mathfrak{h} \mathfrak{e}$
}

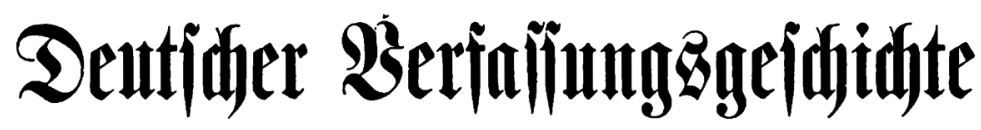

1867-1897

טon

p. \#I Peppel.

(E) $\mathfrak{x}$ it $\mathfrak{B} \mathfrak{B} \mathfrak{n} \boldsymbol{d}$.

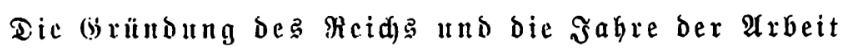
(1867-1877).

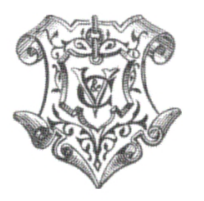

Reipzig,

$\mathfrak{B e r l a g}$ bon $\mathfrak{B e i t} \&$ (romp.

1900. 
